\title{
O ensino superior brasileiro: novas configurações e velhos desafios
}

\section{Higher education in Brazil: new configurations and old challenges}

\author{
Antônio Joaquim Severino*
}

\begin{abstract}
RESUMO
O trabalho apresenta, de uma perspectiva filosófico-educacional, uma análise e reflexão sobre a situação atual do ensino superior público no Brasil, mostrando não só o amplo e contínuo processo, conduzido pelo Estado, de sua reconfiguração organizacional e administrativa mas também a ambígua política educacional que subjaz a esse processo. Para tanto, retoma as formulações legais e descreve algumas iniciativas governamentais que vêm buscando implementar uma permanente reforma universitária com vistas à adequação do ensino superior nacional às consígnias do modelo societário capitalista neoliberal, implementado pela elite brasileira, neste quadrante da história do país. Explicita-se então o dilema fundamental vivido pela sociedade brasileira, representado pelo confronto entre uma educação baseada na teoria do capital humano e uma educação inspirada na teoria da emancipação humana. A educação superior pública é atingida em cheio por essa intencionalidade ideológica, levando-se em conta sua importância no processo de construção da vida social, seja no âmbito do trabalho, da sociabilidade e da cultura, o que torna ainda mais difícil a construção, pelas universidades públicas, de seu projeto político-educacional, tarefa a que se entregam numa postura de luta contra-ideológica.

Palavras-chave: educação brasileira, ensino superior, universidade, política educacional.
\end{abstract}

\footnotetext{
* Professor da Faculdade de Educação da Universidade de São Paulo.
} 


\begin{abstract}
The work presents, from a philosophical and educational perspective, an analysis and reflection on the current situation of public higher education in Brazil, showing not only the large and ongoing process conducted by the State of its organizational and administrative reconfiguration, but also the ambiguous underlying educational policy for this process. For these reasons, it incorporates legal formulations and outlines some governmental initiatives that have sought to implement a permanent university reform pertaining to the suitability of higher education requirements of the societary capitalist neoliberal model, which implemented by the Brazilian elite during this period in history. It then goes on to clarify the fundamental dilemma experienced by Brazilian society, represented by the confrontation between an education based on the theory of human capital and an education system inspired by the theory of human emancipation. Public higher education is achieved in full by that ideological intent, taking into account its importance in the construction of social life, be it in the workplace, social life or in culture. This would make it more difficult for public universities to construct their own educational policy, as this task would place them in a struggle that would go against their ideology.

Key words: Brazilian education, higher education, university, educational policy.
\end{abstract}

\title{
Introdução
}

No contexto da cultura brasileira contemporânea, o ensino universitário tem sua importância proclamada tanto pela retórica oficial como pelo senso comum predominante no seio da sociedade. É-lhe atribuída significativa participação na formação dos profissionais dos diversos campos e na preparação dos quadros administrativos e das lideranças culturais e sociais do país, sendo visto como poderoso mecanismo de ascensão social, cabendo destacada valorização para o ensino oferecido pelas universidades públicas. Introduzido no Brasil apenas na terceira década do século XX, o desenvolvimento do modelo universitário no país marcou-se pela combinação de dois traços fundamentais: $\mathrm{o}$ caráter privado de sua dependência administrativa e a sua natureza de instituição isolada, como que recuperando e consolidando a tradição fundadora iniciada nos idos do Império com as faculdades de Direito, Medicina e Engenharia. Quando se observa o quadro atual de instituições de ensino superior, bem como 
sua evolução a partir dos anos setenta do século passado, impressiona ver o crescimento da iniciativa privada em relação às iniciativas do poder público. Das 2.165 instituições registradas pelo Cadastro do INEP, de 2005, apenas 231 são instituições públicas, o que corresponde a 10,7\% do total. Em 1996, as instituições públicas respondiam ainda por $23 \%$; a queda atual mostra bem a tendência do desenvolvimento desse setor educacional. Das 922 entidades então cadastradas, 211 eram públicas e 711 particulares. (TRIGUEIRO, s/d). Essa dupla tendência mostra a força do modelo de instituição isolada frente ao modelo universitário propriamente dito, e o peso da opção privatizante no setor educacional ${ }^{1}$. Depois de esperar séculos para que se inicie no país a criação de uma experiência de ensino superior minimamente sistematizada, que só começa na terceira década do século passado, essa experiência vai se instalar e desenvolver-se predominantemente sob essas duas configurações. De resto, fica a demonstração de uma realidade extremamente heterogênea, sob todos os aspectos, do sistema de ensino superior no país, com diferenciadas organização e cultura. Heterogeneidade estrutural e instabilidade temporal, uma vez que esse segmento de ensino não encontrou ainda seu modo de ser, manifestando-se constantemente em processo de transformação, em metamorfose permanente.

O que ocorre, no momento, quando o país é envolvido no movimento de uma nova reforma universitária é mais uma demonstração dessa instabilidade. Parece que estamos sempre correndo atrás de uma situação nunca alcançável, numa expectativa de que o ensino superior se adequasse de uma forma definitiva ao tecido das exigências do modelo de sociedade do momento. Desta feita, a busca vai no sentido de adaptá-lo às consígnias do contexto societário capitalista neo-liberal, que, no âmbito da globalização econômica e cultural, se impôs à sociedade brasileira.

Neste trabalho, após tecer minhas análises e reflexões sobre a situação atual do ensino superior público no Brasil, vou me reportar a alguns pressupostos teóricos sobre o sentido de uma universidade que, funcionária do conhecimento, pudesse colocá-lo a serviço da sociedade. Comprometida com o conhecimento, a universidade precisa estar comprometida também, por decorrência, com a extensão e a pesquisa, tanto quanto com o ensino. Lugar de produção, sistematização e disseminação do conhecimento, a universidade brasileira precisa ser mediação da cidadania e da democracia.

\footnotetext{
${ }^{1}$ No entanto, essa proporção deve ser vista mais com relação ao aspecto administrativo, atentando-se para outro fato significativo: quando se leva em conta os números referentes às matrículas efetivas, os dados se invertem. Das 4.453.156 matrículas existentes em 2005, ainda segundo o INEP, $70,6 \%$ delas se dão nas universidades e centros universitários e só $29,4 \%$ em faculdades isoladas. (INEP., 2005).
} 
Este compromisso da educação, em geral, e da Universidade, em particular, com a construção de uma sociedade na qual a vida individual seja marcada pelos indicadores da cidadania, e a vida coletiva, pelos indicadores da democracia, tem sua gênese e seu fundamento na exigência ético-política da solidariedade que deve existir entre os homens. É a própria dignidade humana que exige que se garanta a todos eles o compartilhar dos bens naturais, dos bens sociais e dos bens culturais, de tal forma que, no limite, nenhum ser humano seja degradado na sua relação com a natureza, no exercício do trabalho, seja oprimido em suas relações sociais, no exercício de sua sociabilidade e seja alienado no usufruto dos bens simbólicos, no exercício de sua inserção na cultura.

\section{O ensino superior diante do cenário histórico-social brasileiro em tempos de globalização}

A problemática da educação superior brasileira não pode ser abordada sem se ter bem presente a consolidação do projeto societário capitalista neoliberal em nosso país, neste início de milênio, consolidação que se dá no contexto do fenômeno mais amplo da globalização da economia e da cultura (SANFELICE, 2003; GOERGEN, 2005; FRIGOTTO, 2006; IANNI, 1995).

Com efeito, quando nos referimos à sociedade brasileira, impõe-se começar reconhecendo o domínio hegemônico, neste quadrante histórico, do modelo societário capitalista neoliberal, opção feita pelas nossas elites, nesta passagem de século e de milênio, sob o impacto de um processo mais amplo que é aquele determinado pelo fenômeno abrangente e avassalador da globalização econômica e cultural. Este processo de globalização da economia capitalista reserva ao Brasil um lugar bem secundário na divisão internacional do trabalho, que marca e modifica profundamente as características internas na esfera econômica, social e cultural (FRIGOTTO, 2006; PAULANI, 2006).

$\mathrm{Na}$ atual conjuntura mundial, o cenário específico em que se encontra a sociedade brasileira é aquele desenhado por um intenso e extenso processo de globalização econômica e cultural, conduzido pela expansão da economia capitalista, que se apóia, política e ideologicamente, no paradigma neoliberal. Por isso, é tendência mundial, que vai impondo a todos os países a minimização do Estado, a total priorização da lógica do mercado na condução da vida social, o incentivo à privatização generalizada, a defesa do individualismo, do consumismo, da competitividade, da iniciativa privada. No concernente à educação, prevalece a teoria do capital humano, ou seja, a da preparação de mão-de-obra 
para o mercado de trabalho. Por sua vez, a ideologia neoliberal encontra apoio teórico nas teses filosóficas que consideram que vivemos uma nova era, aquela de uma pós-modernidade, caracterizada pela superação das grandes teses que lastreavam a modernidade (SANFELICE, 2003; SEVERINO, 2006).

Do ponto de vista de sua formação histórica, o Estado brasileiro se constituiu mediante uma modernização conservadora, sob o modelo de orientalidade, nos termos gramscianos, configurando-se com um aparelho estatal forte frente a uma sociedade civil frágil. O estado precede a nação, tornando-se um estado capitalista economicamente e corporativo socialmente. Os mecanismos de representação de interesses dos segmentos sociais se dão no interior do próprio aparelho de estado: espaços para o movimento sindical, via sindicatos, não via centrais sindicais. A representação, mesmo do segmento burguês, dos empresários, se faz pelas câmaras setoriais e não por meio da própria sociedade civil. $\mathrm{O}$ modo corporativo de representação é uma forma de absorver a auto-consciência da sociedade civil, obstruindo a formação de uma consciência ético-política. A supremacia da classe no poder se dá por dominação e não pela direção político-ideológica. O projeto político da classe dominante não tem o respaldo consensual do conjunto ou da maioria da sociedade. Após a ditadura, na década de 1980, tem início um processo de ocidentalização do estado brasileiro: uma relação mais equilibrada entre o estado e a sociedade civil, o Brasil optando pelo modelo norte-americano (presença de uma sociedade civil forte, bastante desenvolvida e articulada, mas com organização política com partidos frouxos, não programáticos, e corporativismos, fazendo "pequena política"), em detrimento do modelo europeu (organização política centrada em partidos com base social homogênea, não corporativa, mas classista, revelando uma sociedade civil forte e politicamente articulada, fazendo "grande política" (COUTINHO, 2006).

Já do ponto de vista econômico, o Brasil vem experimentando, desde o início da década de 1980, um claro retrocesso no perfil de suas atividades e na forma de sua inserção na produção mundial, produzindo quase que só commodities, com alta escala de produção, baixo preço unitário, simplificação tecnológica e rotinização das tarefas. Daí a redução acentuada da importância do setor industrial brasileiro, como se constata pelo fato de o emprego industrial nacional ter caído de 4,2\% em 1980 para 3,1\% em 2001. O país se transformou num imenso chão de fábrica, o trabalho se dando em precaríssimas condições, com jornadas sem fim e massa de trabalho vivo sem a menor qualificação. Assim, a sociedade brasileira, pela sua elite, fez opção pelo projeto societário capitalista neoliberal, que insere o Brasil na divisão internacional do trabalho como produtor de bens básicos, de pouca elaboração industrial, do que decorre sua condição de associação consentida e de subalternidade com relação à ciência e à tecnologia. Na produção econômica, o país desenvolve apenas o trabalho 
simples, dispensando a necessidade de criação de tecnologia própria, nacional, e conseqüentemente do trabalho complexo, reduzido e concentrado em setores específicos de excelência. Para implementar esse projeto societário, procede-se à reforma do Estado, à reestruturação produtiva e à flexibilização dos direitos dos trabalhadores (FRIGOTTO, 2006; PAULANI, 2006).

Coerente com essa opção política e econômica, a educação, em sua relação com o trabalho, é entendida sob a consígnia da Teoria do Capital Humano, destinando-se em sua prática a formar profissionais em sua imensa maioria para o trabalho simples (GENTILI, 2002).

\section{A legislação e a retórica oficial}

Com relação ao ensino superior, a Constituição de 1988 lhe dedica poucos artigos. O artigo 207, lhe assegura "autonomia didático-científica, administrativa e de gestão financeira e patrimonial, e obedecerão ao princípio de indissociabilidade entre ensino, pesquisa e extensão". No parágrafo $2^{\circ}$ do inciso II do artigo 213, afirma-se que "as atividades universitárias de pesquisa e extensão poderão receber apoio do Poder Público". Evidentemente, ficam implícitos no texto constitucional os demais determinantes relacionados ao ensino superior nos princípios referentes à educação em geral. É assim que a Lei de Diretrizes e Bases da Educação Nacional, aprovada em 1996, vai regulamentar esses princípios constitucionais relacionados ao ensino superior. Ao proceder desse modo, a Lei 9394/96 não faz apenas uma operação jurídico-legislativa formal mas consolida igualmente as opções políticas do Estado brasileiro como também suas opções ideológicas.

No texto legal, além dos dispositivos concernentes à educação em geral, auto-aplicáveis também ao ensino superior, é dedicado todo um capítulo, o IV, à educação superior, indo do artigo 43 ao 57. São estabelecidas suas finalidades (art. 43), definidos seus cursos e programas (art. 44) - estabelecendo-se que ela será ministrada em instituições de ensino superior públicas ou privadas, com variados graus de abrangência ou especialização (art. 45) - regulamentados os processos de autorização e reconhecimento dos cursos (art. 46), definido o ano letivo regular (art. 47); trata da emissão dos diplomas (art. 48), das regras de transferências de alunos (art. 49), da disponibilidade das vagas não preenchidas para alunos não regulares (art 50), das normas de seleção e admissão dos alunos (art. 51), das características que as instituições devem ter em função de seu perfil formativo pluridisciplinar (art. 52), do regime jurídico e de carreira docente do pessoal das universidades públicas e do compromisso da União em assegurar 
recursos orçamentários suficientes para a manutenção das instituições federais (art. 55). No art. 56, determina-se que as instituições públicas de ensino superior “obedecerão ao princípio da gestão democrática, assegurada a existência de órgãos colegiados deliberativos, de que participarão os segmentos da comunidade institucional, local e regional". E o artigo 57 estabelece que "o professor ficará obrigado ao mínimo de oito horas semanais de aulas".

Como observa Saviani, "a questão da regulamentação da nova LDB configura uma situação no mínimo curiosa. É que ela não tinha ainda sido aprovada e já estava sendo regulamentada" (SAVIANI, 1998, p. 7). O autor se refere ao fato de o poder público, ansioso em impor determinadas medidas político-administrativas de seu interesse, fazer aprovar uma série de leis e decretos, alguns mesmo antes de aprovação da própria LDB. E é interessante observar que a maioria dos dispositivos antecipados estão relacionados ao ensino superior público. Assim, em 24 de novembro de 1995, foi aprovada a Lei 9.131, dispondo sobre as atribuições do Conselho Nacional de Educação; e no dia 21 de dezembro desse mesmo ano, foi a vez da Lei 9.192, que trata da forma de escolha dos dirigentes das instituições de ensino superior.

No que concerne à Lei 9.131, embora seja atribuída ao CNE uma função abrangente relacionada à toda educação, sente-se claramente que os principais problemas que a lei quer contornar dizem mesmo respeito ao ensino superior. É por isso que se dá destaque às atribuições da Câmara do Ensino Superior, além da dedicação dos artigos $3^{\circ} \mathrm{e} 4^{\mathrm{a}}$ que visam regulamentar o teor dos futuros incisos VI, VIII e IX do artigo $9^{\circ}$ da nova LDB que, no entanto, a essa altura ainda não estava aprovada, concernentes ao ensino superior. São estes dispositivos que introduzirão a sistemática dos exames de avaliação do desempenho dos cursos das instituições universitárias, públicas e privadas.

Já a Lei 9.192, alterando dispositivos da Lei 5.540, busca dar nova regulamentação ao processo de escolha de dirigentes universitários ao mesmo tempo que estabelece, regulamentando o parágrafo único do art. 56 da LDB, que os órgãos colegiados devem ter "o mínimo de setenta por centro de membros do corpo docente no total de sua composição".

São editados pelo governo mais dois decretos para regulamentar essas leis. O Decreto 1.916, de maio de 1996, regulamenta dispositivos da Lei 9.192, no que concerne aos processos de escolha dos dirigentes das instituições federais, e o Decreto 2.026, de outubro de 1996 (posteriormente substituído pelo Decreto 2.306, de abril de 2007) regulamenta os dispositivos relacionados ao exame nacional de curso, apelidado de "provão", na época.

O investimento prioritário na regulamentação de dispositivos relativos ao ensino superior continua mesmo depois de aprovada a nova LDB, evidenciando um processo explícito de uma reforma universitária permanente e capilar. No 
mínimo, fica claramente assumida a política de ensino superior que, no meu entendimento, não responde apenas às exigências de regulamentação formal da LDB, mas sobretudo consagra uma tomada de posição francamente adepta das consígnias da visão neoliberal da educação. Assim, o Decreto 2.306, de agosto de 1997, nova versão do Decreto 2.026, constitui uma verdadeira reforma universitária, sob essa inspiração...

O teor desse Decreto abrange as formas de organização das entidades mantenedoras privadas de ensino superior $\left(\operatorname{art.} 1^{\circ}\right)$, as condições de funcionamento das entidades sem fins lucrativos (art. $2^{\circ}$ ), com destaque para as instituições comunitárias, confessionais e filantrópicas (art. $3^{\circ}$, assim como as entidades com fins lucrativos art. $4^{\circ}$ e $7^{\circ}$ ). É neste Decreto que são classificadas as instituições do sistema federal de ensino superior, regulamentando o que dispunha o art. 45 da LDB (art. $5^{\circ}$ e $6^{\circ}$ ) do ponto de vista de sua manutenção, no art. $8^{\circ}$ estabelecendo sua classificação quanto à organização acadêmica, consagrando a famosa divisão entre universidades, centros universitários, faculdades integradas, faculdades, institutos superiores. $\mathrm{O}$ artigo $9^{\circ}$ caracteriza as universidades enquanto o artigo 12 descreve os centros universitários. O regime de tempo integral é regulamentado pelo artigo $10^{\circ}$ e a criação/incorporação de cursos de graduação fora da sede, pelo artigo 11. Outros processos são regulamentados pelo Decreto: a intervenção do MEC nas instituições de ensino superior (art.13), a autorização e reconhecimento de cursos e credenciamento de instituições (art. 15), criação de cursos da área da saúde (art. 16), do Direito (art. 17), a publicização anual dos critérios de seleção de alunos (art. 18), a comprovação, pelas instituições particulares, de cumprimento do requisito de um terço de seu corpo docente em tempo integral e com qualificação pós-graduada (art. 19). O artigo 20 trata da transição entre o antigo e o novo regime.

Esse fulminante ardor legislativo expressa bem, de um lado, a adesão explícita à via da privatização, pela "admissão aberta e franca das instituições educacionais com fins lucrativos"; de outro, a aceitação de que pode haver boa formação universitária sem produção de conhecimentos, sem pesquisa na área de ensino a que uma instituição se dedica (SAVIANI, 2003, p. 14-15). Essas duas opções se conformam plenamente à agenda neoliberal para a cultura, ciência e educação.

$\mathrm{Na}$ mesma direção, orientam-se outras medidas relativas à política educacional do país, tomadas pelo governo brasileiro atual, bem como medidas administrativas tomadas pelo MEC. Cabe citar, entre outros, o Plano Nacional de Educação, de 2001, o PDE, de 2007, e vários Programas Especiais, como o PROUNI e o REUNI. 
No início desta década, em 2001, é aprovado o Plano Nacional de Educação, que se destaca por sua abrangência. O artigo 214 da Constituição determina que

a lei estabelecerá o plano nacional de educação, de duração plurianual, visando à articulação e ao desenvolvimento do ensino, em seus diversos níveis, e à integração das ações do poder público que conduzam à:

I - erradicação do analfabetismo;

II - universalização do atendimento escolar;

III - melhoria da qualidade do ensino;

IV - formação para o trabalho;

V - promoção humanística, científica e tecnológica do País.

A mesma determinação é retomada no parágrafo $1^{\circ}$ do art. 87 , da nova LDB, em suas Disposições Transitórias:

\begin{abstract}
A União, no prazo de um ano a partir da publicação desta Lei, encaminhará ao Congresso Nacional, o Plano Nacional de Educação, com diretrizes e metas para os dez anos seguintes, em sintonia com a Declaração Mundial sobre Educação para Todos.
\end{abstract}

No entanto, cumprir essa determinação legal, de acordo com vários estudos (VALENTE e ROMANO, 2002; DOURADO, 2007), parece que não era intenção claramente assumida pelo governo da época, tanto que quem primeiro encaminha à Câmara dos Deputados um Projeto de Plano foi a própria sociedade civil organizada, a partir de iniciativas do Fórum Nacional em Defesa da Escola Pública. Quando protocolado esse projeto, o governo desengaveta o seu, que passou a ser então um anexo do Projeto da Sociedade.

A ofensiva governamental e a postura pouco autônoma dos deputados logo fizeram prevalecer o projeto oficial, impondo a concepção do Executivo. E mais uma vez esse documento legal tende a limitar-se a declarações de intenções, pois mecanismos concretos de financiamento não foram definidos. Não bastasse isso, o Plano ainda sofreu nove vetos do Presidente da República, vetos que não foram sequer apreciados pelos congressistas, mantendo assim a limitação de recursos 
para a educação (Lei 10.172, de 09/01/2001). Também não foram elaborados os Planos Estaduais de Educação que deveriam, por força da própria Lei do PNE (ABICALIL, 2005). No que diz respeito ao ensino superior, o Plano estabelece como meta atingir $30 \%$ de matrículas em dez anos.

Em 2007, o governo lança o PDE, Plano de Desenvolvimento da Educação (PDE 2007), com uma série de medidas com as quais o governo espera melhorar o desempenho das instituições educacionais de todos os níveis. Embora mais voltado para a educação básica, o Plano tem, no concernente à educação superior, duas metas principais: a ampliação do acesso e a articulação entre os programas de financiamento do ensino superior. As universidades federais que abrirem ou ampliarem cursos noturnos e reduzirem o custo/aluno vão ganhar mais verbas. A meta é dobrar o número de vagas (hoje são 580 mil). Outra meta é a articulação entre o Fies e o ProUni, que permitirá o financiamento de $100 \%$ das bolsas parciais do ProUni e a quitação da dívida ativa consolidada das instituições de ensino superior. O novo programa pode gerar 100 mil vagas por ano.

Com o Decreto 6.096, de 24 de abril de 2007, o governo instituiu o Reuni, Programa de Apoio a Planos de Reestruturação e Expansão das Universidades Federais, visando ao aumento do número de vagas para o ingresso de estudantes, redução da evasão, maior mobilidade estudantil e maior interação entre as universidades e o ensino básico, profissional e tecnológico. As universidades apresentam seus planos e, uma vez aprovados, elas receberão maior volume de recursos extras.

Todas essas mudanças, resultantes da nova legislação, de planos gerais e programas específicos, desde os anos noventa do século findo, estão desempenhando um ambíguo papel na vida social do país. Sempre embalado num discurso retórico em defesa da qualidade do ensino e da excelência da educação, e dos decorrentes corolários, a democratização da sociedade, a realização da cidadania, a melhoria de vida para seus destinatários diretos e indiretos, incluindo aí a inclusão no mercado de trabalho, o governo toma iniciativas alegadamente fundadas em argumentos técnicos e vai implementando ações nem sempre articuladas em torno de um projeto político-educacional orgânico. Tem sido característico dos governos neoliberais contemporâneos o apropriar-se "com eficiência de idéias defendidas por setores progressistas, em recontextuá-las, em distorcê-las e em fazê-las funcionar a favor de outros interesses" (MOREIRA, 2001, p. 11). Ocorre então um complexo emaranhado de conceitos, valores, idéias e posições entre os diferentes segmentos da sociedade envolvidos nos processos sociais. Assim, as palavras se tornam socialmente polissêmicas, atropeladas por usos desvirtuados pela administração burocrática, pelo senso comum, pelos intelectuais orgânicos do sistema, desviando-se de seu sentido originário. É o que parece estar acontecendo com o próprio sentido da existência da univer- 
sidade, que já não parece tão claro. Percebe-se que, além das críticas oriundas de setores especializados, uma espécie de questionamento generalizado, difuso em todo o corpo social, se faz cada vez mais presente e explícito. Sem dúvida, o sentimento geral de frustração em relação às expectativas não realizadas e às promessas não cumpridas de desenvolvimento e progresso das sociedades, a desvalorização da cultura elaborada e a banalização das referências em todos os setores da vida humana, são causas abrangentes que levam igualmente à desvalorização da universidade. E os diversos atores sociais envolvidos na crise do ensino superior entram num conflito permanente que acaba comprometendo quaisquer resultados que pudessem ser úteis para a sociedade.

Nesse contexto de ambigüidades e ambivalências, os conceitos perdem sua força e o discurso vira ruído. A fala dos supostos responsáveis pelo bem público indica uma direção, mas a realidade das coisas caminha na direção inversa. Por isso mesmo, os espíritos ficam confusos, perdendo a lucidez na visão das coisas humanas.

A significação da universidade se dilui nesse emaranhado de idéias e proposições, como indicação de que a humanidade teria entrado numa nova era, que superaria tudo o que havia construído e acumulado. Com efeito, tornou-se corrente e recorrente a afirmação incisiva de que estaríamos vivendo hoje, às vésperas do terceiro milênio, um mundo totalmente diferente daquele projetado pela visão iluminista da modernidade e destinado à realização de uma sociedade utópica. Chega-se ao ponto de afirmar que a história teria terminado, uma vez que a civilização humana teria alcançado o patamar mais alto do progresso possível para a humanidade. Já se encontrariam realizadas todas as possibilidades de aperfeiçoamento, de aprimoramento de nossas condições de vida individual e social (FUKUYAMA, 1992). O modelo de existência humana não é mais um ponto no horizonte futuro, mas já estaria disponível no presente, faltando apenas que cada pessoa ou cada grupo a ele se ajustasse. Estaríamos vivendo um momento de plena revolução tecnológica, capaz de lidar com a produção e transmissão de informações em extraordinária velocidade, num processo de planetarização não só da cultura mas também da economia e da política. Tratar-se-ia de um momento marcado pelo privilegiamento da iniciativa privada, pela minimalização da ingerência do Estado nos negócios humanos, pela maximalização das leis do mercado, pela ruptura de todas as fronteiras e barreiras entre estados e mercados. No plano mais especificamente filosófico, estaria em pauta uma crítica cerrada às formas de expressão da razão teórica da modernidade, propondo-se a desconstrução de todos os discursos por ela produzidos, todos colocados sob suspeita, inclusive aqueles da própria ciência. Este mundo novo dispensa a universidade tradicional, forjada à luz das referências da modernidade, uma de suas expressões mais arrematadas. 
O poder público brasileiro, desde meados dos anos de 1990, busca implementar, com base na legislação e em seus programas, uma política de diversificação e diferenciação, com vistas a reconfigurar o sistema de educação superior, associando os princípios de flexibilidade, competitividade e avaliação (OLIVEIRA, 2007, p. 11), bem no ritmo das pressões da agenda neoliberal que vem se impondo hegemonicamente nas últimas décadas. Esse processo vai ao encontro à forte tendência de mercantilização dos serviços educacionais e à conseqüente privatização do ensino superior, sempre com a alegação da necessidade de atender melhor às demandas sociais, bem como aquelas do mercado de trabalho. Mas, na verdade, o que se tem em vista é atender mesmo ao mercado de trabalho, bem na linha do que estipula a teoria do capital humano.

Nesse contexto de transformações necessárias mas sob direcionamento forçado, as universidades públicas "lutam, portanto, entre ajustar-se às políticas de educação superior e às demandas do mercado e desenvolver um projeto político-pedagógico próprio, coerente com a construção de sua autonomia" (OLIVEIRA, 2007, p. 18). O risco que ela corre é o de tornar-se, por força desse processo induzido de ajuste e regulação do sistema, uma universidade muito dependente das imposições políticas e das metas do poder executivo do país, mercantilizando sua produção acadêmica.

Como decorrência, demonstra um modelo de gestão universitária e um modo de produzir o trabalho acadêmico que pode se distanciar cada vez mais do histórico ideal de liberdade acadêmica e de trabalho intelectual autônomo, resultando, por vezes, em uma resposta funcionalista à indução das políticas de educação superior e às demandas contemporâneas, afirma ainda e com razão, Oliveira. (2007, p. 18)

Enquanto as instituições universitárias privadas seguem, convictas, a lógica do mercado na oferta de seus serviços educacionais, as universidades públicas, assim como a educação pública em geral, se debate num confronto de múltiplas frentes. Enfrentam a necessidade de inovar para atender às justas necessidades surgidas no seio da sociedade por força de sua complexificação, modernização e desenvolvimento, ao mesmo tempo que se vêem constrangidas a resistir às induções e determinações que lhe são feitas pela política neoliberal imperante, o que, muitas vezes, leva seus defensores a ter de assumir uma posição vista como conservadora. E, como conclui Oliveira, ao analisar o processo de metamorfose das universidades públicas federais, a partir da década de 1990, 
[...] nesse processo de ajustamento, de sobrevivência e de desenvolvimento institucional, há indícios de que muitas universidades federais estejam assumindo perfil mais funcional e pragmático, o que pode distanciá-las paulatinamente do ideal de universidade como instituição social que se pauta, sobretudo, pela natureza das suas atividades, pela cultura e história institucional e pelo papel que desempenha no processo de emancipação da sociedade. (OLIVEIRA, 2007, p. 15)

\section{Conclusão}

De todas essas constatações, pode-se concluir que o ensino superior público atravessa um momento histórico-social cheio de desafios. De um lado, enfrenta a pressão do modelo societário capitalista neoliberal, através de seu mediador principal, o poder público nacional, pressionado, por sua vez, pelos agentes internacionais que se impõem em função do jogo geopolítico das forças econômicas próprio do neoliberalismo capitalista globalizado, que responde pela instauração planetária de uma nova ordem mundial (ou seria desordem?), particularmente na esfera da economia. Como bem sintetizam Marques e Bittar,

[...] o modelo neoliberal implementado no Brasil, conforme a lógica capitalista, estabelece, de forma imperativa, algumas mudanças e, entre elas: a privatização de vários órgãos públicos, a desvalorização da moeda (o real), o aumento da dívida interna e externa, o aumento do número de desemprego, a redução dos gastos sociais e a ampliação da concentração de renda. A educação superior considerada como instrumento do desenvolvimento econômico do País, atende cada vez mais às exigências do mercado, transformando a aquisição do saber em um bem privado, especialmente da classe dominante. (MARQUES E BITTAR, 2007, p. 53)

De outro lado, enfrenta igualmente as pressões oriundas da própria sociedade civil, mas de duas naturezas bem distintas. De modo legítimo, a população em geral, premida pelas necessidades da sobrevivência ou identificadas com projetos culturais emancipatórios, reclama a necessária contribuição das universidades públicas, cobrança de retorno mais que justo dos resultados do trabalho desenvolvido nas universidades com financiamento da própria sociedade; mas, 
muitas vezes, essa crítica e cobrança vêm amalgamadas no discurso ideologizado dos intelectuais orgânicos do sistema, que visam, na verdade, minar a própria existência da instituição pública, buscando levantar a opinião da população contra ela, em nome da austeridade no uso dos recursos públicos, da eficiência e da produtividade. Tais intelectuais desempenham explicitamente esse papel, servindo-se, para tanto, de um discurso formalmente crítico e supostamente lastreado em conclusões tecno-científicas, especializado em focar as deficiências e fragilidades do setor público.

Por isso, os atores internos às instituições universitárias se vêem forçados a desencadear simultaneamente iniciativas de inovação e/ou de resistência, de crítica e/ ou de elaboração de propostas de melhoria da qualidade do ensino superior, articuladas à exigência de igual melhoria das condições objetivas para o trabalho de ensino, pesquisa e extensão, que lhe é cobrado. Daí o movimento político dos docentes e funcionários dessas instituições, seja no interior das próprias universidades seja no âmbito de suas associações, no sentido da produção de uma contra-ideologia que responda às investidas do sistema e de seus ideólogos. Luta inglória, atravessada pelas limitações internas aos grupos progressistas e pelas investidas externas, num contexto extremamente adverso, até mesmo hostil, quando se tem o próprio Estado, que teoricamente deveria ser o maior defensor dos interesses públicos, comprometido com interesses ideológicos dos grupos dominantes. Ao invés de estar a serviço dos interesses universais da população, o aparelho estatal atua como se fosse entidade privada, a serviço de interesses particulares.

Essa realidade histórica faz com que a Universidade pública, como instituição responsável pela elaboração de uma nova consciência social, funcionária que deve ser do conhecimento, se encontre marcada por uma dura orfandade, ameaçada na sua própria sobrevivência. Na fala de estudiosos do assunto,

[...] a reconfiguração da educação superior brasileira é parte de intenso processo de reformas, no interior de um radical movimento de transformações político-econômicas em nível mundial, com profundas repercussões no Brasil. Suas conseqüências para a identidade institucional da universidade brasileira serão inevitáveis, se concretizadas tais mudanças conforme diretrizes emanadas originalmente desses organismos multilaterais, em geral tão bem traduzidos domesticamente pelos responsáveis oficiais pela reforma do Estado e da Educação Superior em nosso país. (SILVA JR; SGUISSARDI, 2001, p. 271-272) 
Ou ainda,

\begin{abstract}
A produção de conhecimento - consubstancial à idéia de universidade desde seus primórdios - tende a ser substituída pela administração de dados e informações em um processo de assessoramento ao mercado, o que impõe a sensível perda do necessário distanciamento que essa instituição deve ter em relação à sociedade, da capacidade de reflexão e crítica, característica também histórica da universidade e de qualquer outra categoria de IES. Esse processo de substituição da produção de conhecimento pela administração de dados e informações assemelharia a instituição de educação superior a empresas prestadoras de serviços, organizadas pois para este fim, sem, obviamente, as exigências que se põem desde sempre para aquelas instituições. (SILVA JR; SGUISSARDI, 2001, p. 269)
\end{abstract}

Na verdade, os desafios das universidades públicas são os mesmos de toda a educação pública, em todos os seus níveis e modalidades, resumindo-se no conflito dilemático que atravessa a realidade social brasileira da atualidade: o confronto entre uma educação pautada nas premissas da teoria do capital humano e uma educação que se quer identificada com a teoria da emancipação humana, entre uma educação que se coloca a serviço do mercado e uma outra que se quer a serviço da construção de uma condição de existência mais humanizada, onde o trabalho é uma mediação essencial do existir histórico das pessoas e não um mero mecanismo da produção para o mercado. Sem prejuízo de seu compromisso de preparar as novas gerações para a esfera do trabalho, pelo adequado domínio dos saberes científico e tecnológico, a educação não pode deixar de investir também no amadurecimento de uma nova consciência social e no aprimoramento da formação cultural dessas gerações. Desse núcleo aglutinador de suas tarefas, nenhuma universidade pode abrir mão sob pena de se descaracterizar integralmente e de comprometer sua identidade fundamental.

E é só isso que a sociedade brasileira espera do projeto político-educacional de suas universidades públicas. 


\section{REFERÊNCIAS}

COUTINHO, Carlos N. O estado brasileiro: gênese, crise, alternativas. In: LIMA, Júlio C.; NEVES, Lúcia M. W. Fundamentos da educação escolar no Brasil contemporâneo. Rio de Janeiro: Fiocruz/EPSJV, 2006. p. 173-200.

DOURADO, Luiz F.; CATANI, Afrânio M.; OLIVEIRA, João F. de (Org.). Políticas e gestão da educação superior: transformações recentes e debates atuais. São Paulo: Xamã; Goiânia: Alternativa, 2003.

FRIGOTTO, Gaudêncio. Fundamentos científicos e técnicos da relação trabalho e educação no Brasil de hoje. In: LIMA, Júlio C.; NEVES, Lúcia M. W. Fundamentos da educação escolar no Brasil contemporâneo. Rio de Janeiro: Fiocruz/EPSJV, 2006. p. 241-260.

FUKUYAMA, Francis. O fim da história e o último homem. Rio de Janeiro: Rocco, 1992.

GENTILI, Pablo. Três teses sobre a relação trabalho e educação em tempos neoliberais In: LOMBARDI, J. C.; SAVIANI, D.; SANFELICE, J. L. (Org.). Capitalismo, trabalho e educação. Campinas: Autores Associados/HISTEDBR, 2002. p. 45-59.

GOERGEN, P. Pós-modernidade, ética e educação. Campinas: Autores Associados, 2005 .

IANNI, Octávio. A sociedade global. 3. ed. Rio de Janeiro: Civilização Brasileira, 1995.

LIMA, Júlio C.; NEVES, Lúcia M. W. Fundamentos da educação escolar no Brasil contemporâneo. Rio de Janeiro: Fiocruz/EPSJV, 2006.

MARQUES, Eugênia P. de S.; BITTAR, Mariluce. Reforma universitária e inclusão social: uma análise do Programa Universidade Para Todos (PROUNI) e a inserção dos negros na Universidade. In: PEREIRA, Filomena M. de A.; MULLER, M. Lúcia R. Educação na interface relação estado/sociedade. Cuiabá: EDUFMT/Capes, 2006. v. 1, p. $49-59$.

MOREIRA, A. Flávio. Currículo, cultura e formação de professores. Educar, Curitiba, n. 17, p. 39-52, 2001.

OLIVEIRA, João F. de. Reforma da educação superior: mudanças na gestão e metamorfose das universidades públicas. In: PEREIRA, Filomena M. de A.; MULLER, M. Lúcia R. Educação na interface relação estado/sociedade. Cuiabá: EDUFMT/ Capes, 2006. v. 1, p. 11-21. 
PAULANI, Leda M. O projeto neoliberal para a sociedade brasileira: sua dinâmica e seus impasses. In: LIMA, Júlio C.; NEVES, Lúcia M. W. Fundamentos da educação escolar no Brasil contemporâneo. Rio de Janeiro: Fiocruz/EPSJV, 2006. p. 67-83.

PEREIRA, Elisabete M. de A. Educação geral: com qual propósito. In: Universidade e educação geral: para além da especialização. Campinas: Alínea, 2007. p. 65-92. (Coleção Educação em Debate).

PEREIRA, Filomena M. de A.; MULLER, M. Lúcia R. Educação na interface relação estado/sociedade. v. 1. Cuiabá: EDUFMT/Capes, 2006.

SANFELICE, J. L. Pós-modernidade, globalização e educação. In: LOMBARDI, J. C. (Org.). Globalização, pós-modernidade e educação: história, filosofia e temas transversais. Campinas: Autores Associados/HISTEDBR, 2003. p. 3-12.

SAVIANI, Dermeval. Da nova LDB ao novo Plano Nacional de Educação: por uma outra política educacional. Campinas: Autores Associados, 1998.

SEVERINO, Antonio J. Fundamentos ético-políticos da educação no Brasil de hoje. In: LIMA, Júlio C.; NEVES, Lúcia M. W. Fundamentos da educação escolar no Brasil contemporâneo. Rio de Janeiro: Fiocruz/EPSJV, 2006. p. 289-320.

SILVA JR., J. dos Reis; SGUISSARDI, Valdemar. As novas faces da educação superior no Brasil: reforma do Estado e mudanças na produção. São Paulo: Cortez/CDAPHIFAN, 2001. 